\title{
MEMOIRS
}

\section{OF \\ THE CHEMICAL SOCIETY.}

\section{On some of the Products of the Action of Nitric Acid on Castor Oil. By Thomas George Tilley.}

Read April 27, 1841.

THE action of nitric acid on the fat acids is a subject that has been lately investigated by Laurent* and Bromeis $\dagger$, and the interesting results obtained by them having called the attention of chemists to the subject, I was induced, at the suggestion of Professor Liebig, to examine in his laboratory the products of the oxidation of the oil of Ricinus Communis, differing as it does in such a remarkable degree from the other fixed oils.

One part of this oil was accordingly mixed with twice its weight of nitric acid diluted with an equal bulk of water, and subjected to a gentle heat in a retort. 'The parts which distilled over were preserved. After some time the action became very violent, and gas was formed in such quantities as to expel the contents of the retort forcibly from its mouth. The retort must then be removed from the fire, when the action gradually subsides. When again placed on the fire, protected by a sand-bath, the action is not so violent. The process of oxidation must be continued for some days, more or less, according to the strength of the nitric acid employed. When the quantity of nitrous acid fumes decreases, the retort is removed from the fire. In the receiver are found nitric acid, water, and a peculiar volatile oily acid, which new compound will form the subject of the following pages. If the

* Ann. de Chim. et de Phys., Ixvi.

$\dagger$ Annalen der Pharmacie, xxxv. p. 86. [Noticed in Philosophical Magazine for February, vol. 18. p. 115.]

Chem.Soc. Mem. vol. I. 
fatty mass which remains in the retort be mixed with water and distilled, an additional quantity of the acid will be obtained.

It must be separated from the acid fluid on which it floats, mixed with water and redistilled, which process must be repeated several times. After this it must be dried by standing over melted phosphoric acid, chloride of calcium not being adapted to the purpose, it being a little soluble in the acid.

The acid procured in this way is perfectly colourless and transparent, having an agreeable aromatic smell and a sweet stimulating taste. It is sparingly soluble in water, imparting to that fluid its peculiar smell. It is soluble in nitric acid, alcohol and æther. When raised to the temperature of $148^{\circ} \mathrm{C}$. it begins to boil, and a small part distils over; but if kept for some time at that temperature, it becomes black and is decomposed, giving off empyreumatic products, so that it cannot be distilled alone. It burns with a clear flame, giving little smoke. It does not become solid though cooled to $-17^{\circ} \mathrm{C}$. To this body I have given the name of Enanthylic Acid, for reasons which will be stated in another part.

To determine its composition the acid was burned with oxide of copper. water,

l st. 0.3305 substance gave 0.7810 carbonic acid, and 0.3330

2nd. 0.4295 substance gave 0.9905 carbonic acid, and 0.4 .009 water.

This gives in 100 parts,

\begin{tabular}{lcc} 
& 1 1st. & 2nd. \\
Carbon.......... & $65 \cdot 34$ & $65 \cdot 33$ \\
Hydrogen..... & $10 \cdot 83$ & $10 \cdot 60$ \\
Oxygen...... & $23 \cdot 83$ & $24 \cdot 07$ \\
\cline { 2 - 3 } & $\frac{100 \cdot 00}{100 \cdot 00}$
\end{tabular}

Enanthylic Ather.-This æther is formed by dissolving the acid in strong alcohol, and passing a stream of hydrochloric acid gas through the solution. To the mixture is then added carbonate of potash, in order to neutralize all free acid; it is then distilled. The ather passes over into the receiver, and may be freed from any alcohol that it may contain by agitation with water. It must, lastly, be distilled over chloride of calcium in a stream of carbonic acid gas, as it is decomposed by the oxygen of atmospheric air, at the temperature of its boiling point.

The onanthylic æther so obtained is a colourless fluid, lighter than water, having a peculiar and agreeable smell not unlike that of nitrobenzide. It has a sweet and somewhat 
pungent taste, leaving a disagreeable sensation on the palate. It is soluble in æther and alcohol, and burns with a clear blue flame, giving out no smoke. It is solid at the temperature produced by a mixture of snow and salt, and is then crystalline.

Burnt with oxide of copper, 0.2195 substance gave 0.5485 carbonic acid, and 0.3195 water; making in 100 parts,

$\begin{array}{lll}\text { Carbon......................... } & 68.57 \\ \text { Hydrogen .................. } & 11.57 \\ \text { Oxygen .................... } & 19 \cdot 86\end{array}$

$100 \cdot 00$

and leading to the following composition :-

$$
\begin{array}{rrr}
18 \text { atoms Carbon ..... }= & 1375.80 & 68.71 \\
18, " \text { Hydrogen .. } & 224.63 & 11.22 \\
4 . \quad \text { Oxygen ...... } & 400.00 & 20.07 \\
\hline 2000.43 & 100.00
\end{array}
$$

Now supposing this æther to be composed of one atom oxide of æthyl and one atom of anhydrous acid, we have for the composition of the latter $\mathrm{C}^{14} \mathrm{H}^{13} \mathrm{O}^{3}$, and adding to this one atom of water to form the hydrate, we have, in 100 parts,

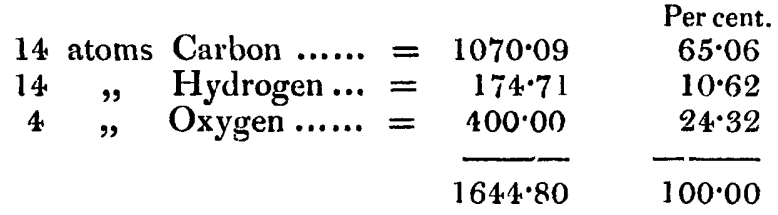

which calculated result agrees with the numbers found by ac tual experiment given at page 2.

Enanthylate of Silver.-This salt may be easily prepared by precipitating a neutral ammoniacal solution of the acid by nitrate of silver; it falls in the form of a white flocculent powder.

1st. $0 \cdot 7165$ of this salt gave $\cdot 3265$ silver, which is equivalent to 0.3509 oxide of silver. This gives per cent.,

Oxide of silver................. $48 \cdot 89$

Enanthylic acid.............. $51 \cdot 11$

$-100 \cdot 00$

making the atomic weight of the anhydrous acid $1517^{\circ} 0$, the calculated result being $1532 \cdot 33$.

By burning the salt dried in vacuo over sulphuric acid, with oxide of copper, 0.7350 gave 0.9360 carbonic acid, and 0.3675 water. 
2nd. 0.8785 gave $1 \cdot 1300$ carbonic acid, and 0.4505 water. This gives in 100 parts,

\begin{tabular}{|c|c|c|}
\hline & lst. & 2nd. \\
\hline Carbon ........ & $35 \cdot 20$ & $35 \cdot 56$ \\
\hline Hydrogen .... & $5 \cdot 55$ & $5 \cdot 68$ \\
\hline Oxygen.......... & 10.27 & $9 \cdot 78$ \\
\hline Oxide of silver. & $48 \cdot 89$ & $48 \cdot 98$ \\
\hline & 100 & 100 \\
\hline
\end{tabular}

and leads to the following theoretical composition :-

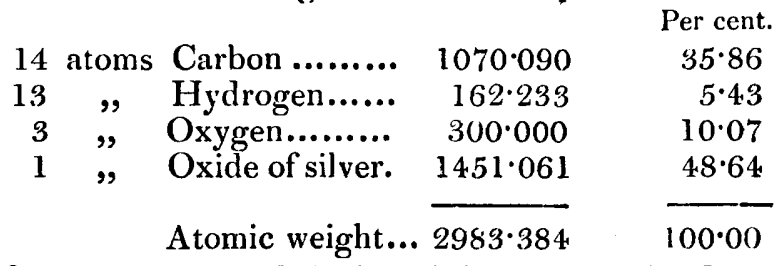

The formula for this salt is then $\mathrm{C}^{14} \mathrm{H}^{13} \mathrm{O}^{3}+\mathrm{Ag} \mathrm{O}$.

Enanthylate of Baryta. - This salt is formed by boiling carbonate of baryta with an alcoholic solution of enanthylic acid till the fluid no longer possesses acid reaction. The solution must be filtered while hot, and on cooling deposits the salt in beautiful pearly scales, which are insoluble in æther, but soluble in water and alcohol.

0.3520 of this salt gave 0.1735 carbonate of baryta, or $0 \cdot 1346$ baryta, the atomic weight of the acid, calculated from this, being $1545 \cdot 54$. It gives in 100 parts, 38.23 oxide of barium $61 \cdot 77$ œnanthylic acid

\section{$100 \cdot 00$}

1st. $0 \cdot 4,395$ of the same salt, burned with oxide of copper, gave 0.6645 carbonic acid, and $0 \cdot 2740$ water.

2nd. 0.3460 salt gave 0.5200 carbonic acid, and 2190 water.

After adding to the carbon that which remained, combined as carbonic acid, with the baryta in the combustion tube, we obtain in 100 parts,

\begin{tabular}{lrr} 
Carbon........... & 44.84 & 44.58 \\
Hydrogen ....... & 6.91 & 6.87 \\
Oxygen .......... & 10.02 & 10.32 \\
Baryta .......... & 38.23 & 38.23 \\
\cline { 2 - 3 } & $\frac{100.00}{100.00}$
\end{tabular}


which gives the following theoretical numbers:-

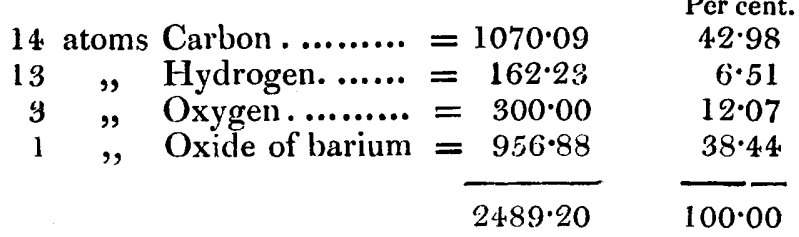

It will be seen by the preceding numbers that an excess of carbon is found; but this may be accounted for by the high temperature required to burn the last particles of carbon, by which some of the carbonic acid might have been driven off from the carbonate of baryta in the combustion tube.

The formula for this salt is one atom cenanthylic acid and one atom oxide of barium, or $\mathrm{C}^{14} \mathrm{H}^{13} \mathrm{O}^{3}+\mathrm{BaO}$.

Enanthylate of Potash is obtained by neutralizing the carbonate of that alkali by onanthylic acid; it does not crystallize, but, on evaporation, assumes the form of a thick transparent jelly.

The Copper Salt crystallizes in beautiful needles of a rich green colour, soluble in alcohol, and sparingly so in water.

The Enanthylate of Strontian appears in the form of bright pearly scales, very much resembling the analogous salt of baryta.

It will at once be perceived by the analyses which have been given, that the composition of anhydrous cenanthylic acid is $\mathrm{C}^{14} \mathrm{H}^{13} \mathrm{O}^{3}$, and it enters as such into the following combinations :-

QEnanthylate of water.......... $\mathrm{C}^{14} \mathrm{H}^{13} \mathrm{O}^{3}+\mathrm{H}^{2} \mathrm{O}$

$$
\begin{array}{ccc}
" & \text { oxide of æathyl. } \mathrm{C}^{14} \mathrm{H}^{13} \mathrm{O}^{3}+\mathrm{C}^{4} \mathrm{H}^{5} \mathrm{O} \\
" & " \quad \text { barium } \mathrm{C}^{14} \mathrm{H}^{13} \mathrm{O}^{3}+\mathrm{BaO} \\
" & \Rightarrow \quad \text { silver. } \mathrm{C}^{14} \mathrm{H}^{13} \mathrm{O}^{3}+\mathrm{Ag} \mathrm{O} .
\end{array}
$$

Now it was discovered some time ago that wine owes its peculiar smell to a certain acid in combination with oxide of æthyl. To this acid Liebig and Pelouze, its discoverers, gave the name œnanthic acid (flower of wine). Enanthic acid has the following composition, $\mathrm{C}^{14} \mathrm{H}^{13} \mathrm{O}^{2}+$ aq.

The analogy between this acid and the one described in this paper will at once be seen, and the composition of the two acids would lead us to suppose that they are oxides of the same radical, which may for the present be considered as composed of $\mathrm{C}^{14} \mathrm{H}^{13}$; while the two acids are respectively

$$
\begin{aligned}
& \mathbf{R}+2 \mathrm{O} \\
& \mathbf{R}+3 \mathrm{O} .
\end{aligned}
$$

On these grounds I have given the higher oxide the name Enanthylic acid, and propose for the lower oxide, that of 
Liebig and Pelouze*, the name Enanthylous acid. It is not improbable that onanthylic acid may be identical with the azoleinic acid of Laurent+; but he did not obtain it in a state of purity. When the œnanthylate of silver is distilled, there pass into the receiver an oil and a solid body, neither of which possesses acid properties. The solid body is soluble in hot alcohol, and on being allowed to cool, it crystallizes in beautiful needles.

Suberic acid is another product of the oxidation of castor oil; it remains in the retort mixed with oxalic acid: it may be purified by repeated crystallizations, and boiling with nitric acid.

Thus obtained and dried at $100^{\circ} \mathrm{C}$, 0.2710 substance gave .5490 carbonic acid, and 0.1990 water, or, in 100 parts, Found. Atoms. Calculated.

\begin{tabular}{lrrr} 
Carbon .... & 55.97 & 8 & 55.64 \\
Hydrogen . & 8.15 & 7 & 8.03 \\
Oxygen ... & 35.78 & 4 & 36.33 \\
\cline { 2 - 3 } & & & 100.00
\end{tabular}

giving the formula $\mathrm{C}^{8} \mathrm{H}^{6} \mathrm{O}^{3}+$ aq.

The other acids found by Laurent did not appear to have been formed; but this is not affirmed with positive certainty, as the examination was not proceeded with. A trace of lipinic acid, however, may be obtained during the evaporation of the fluid parts, pressed from the suberic acid. 